\title{
Associations of DMT therapies with COVID-19 severity in multiple sclerosis
}

Steve Simpson-Yap ${ }^{1,2,3} \&$ Edward De Brouwer ${ }^{4}$, Tomas Kalincik ${ }^{1,5}$, Nick Rijke ${ }^{6}$, Jan Hillert ${ }^{7}$, Clare Walton ${ }^{6}$, Gilles Edan ${ }^{8}$, Yves Moreau $^{4}$, Tim Spelman $^{7,9}$, Lotte Geys $^{10}$, Tina Parciak ${ }^{10,11}$, Clément Gautrais ${ }^{12}$, Nikola Lazovski ${ }^{13}$, Ashkan Pirmani ${ }^{4,10}$, Amin Ardeshirdavani ${ }^{4}$, Lars Forsberg $^{7}$, Anna Glaser ${ }^{9}$, Robert McBurney ${ }^{14}$, Hollie Schmidt ${ }^{14}$, Arnfin Bergmann ${ }^{15}$, Stefan Braune $^{15}$, Alexander Stahmann ${ }^{16}$, Rodden Middleton ${ }^{17}$, Amber Salter ${ }^{18,19}$, Robert J. Fox ${ }^{18,20}$, Anneke van der Walt ${ }^{21}$, Helmut Butzkueven ${ }^{21}$, Raed Al-Roughani ${ }^{22}$, Serkan Ozakbas ${ }^{23}$, Juan I Rojas $^{24,25}$, Ingrid van der Mei ${ }^{26}$, Nupur $\mathrm{Nag}^{2}$, Rumen Ivanov ${ }^{27}$, Guilherme Sciascia do Olival $^{28}$, Alice Estavo Dias ${ }^{28}$, Melinda Magyari ${ }^{29}$, Doralina Guimarães Brum ${ }^{30,31}$, Maria Fernanda Mendes ${ }^{31,32}$, Ricardo Alonso ${ }^{25,33}$, Richard Nicholas ${ }^{17,34,35}$, Johana Bauer ${ }^{36}$, Anibal Chertcoff $^{37}$, Ana Zabalza ${ }^{38}$, Georgina Arrambide ${ }^{38}$, Alexander Fidao ${ }^{2}$, Giancarlo Comi ${ }^{39}$, Liesbet M. Peeters ${ }^{10}$

1. CORe, Department of Medicine, The University of Melbourne, Australia; 2.

Neuroepidemiology Unit, Melbourne School of Population \& Global Health, The University of Melbourne, Australia; 3. Menzies Institute for Medical Research, University of Tasmania, Australia; 4. ESAT-STADIUS, KU Leuven, Belgium; 5. Melbourne MS Centre, Department of Neurology, Royal Melbourne Hospital, Australia; 6. MS International Federation, United Kingdom; 7. Department of Clinical Neuroscience, Swedish MS Registry, Sweden; 8. Department of Neurology, CHU Pontchaillou, France; 9. Karolinska Institutet, Sweden; 10. Biomedical Research Institute - Data Science Institute, Hasselt University, Belgium; 11. Department of Medical Informatics, University Medical Center Göttingen, Germany; 12. Department of Computer Science and AI, KU Leuven, Belgium; 13. QMENTA, Spain; 14. 
iConquerMS People-Powered Research Network, Accelerated Cure Project for MS, United

States of America; 15. NeuroTransData Study Group, NeuroTransData, Germany; 16.

German MS-Register by the National MS Society, MS Forschungs- und

Projektentwicklungs-gGmbH, Germany; 17. UK MS Register, Swansea University, United

Kingdom; 18. COViMS, United States of America; 19. Division of Biostatistics, Washington

University in St Louis, United States of America; 20. Mellen Center for Multiple Sclerosis,

Cleveland Clinic, United States of America; 21. Department of Neuroscience, Central

Clinical School, Monash University, Australia; 22. Dokuz Eylul University, Turkey; 23.

Division of Neurology, Department of Medicine, Amiri Hospital, Kuwait; 24. Neurology

Department, Hospital Universitario de CEMIC, Argentina; 25. RELACOEM, Argentina; 26.

The Australian MS Longitudinal Study, Menzies Institute for Medical Research, University

of Tasmania, Australia; 27. Bulgarian SmartMS COVID-19 Dataset, Bulgaria; 28. ABEM -

Brazilian MS Patients Association, Brazil; 29. The Danish Multiple Sclerosis Registry,

Departement of Neurology, University Hospital Rigshospitalet, Denmark; 30. Universidade

Estadual Paulista, Unesp, Faculdade de Medicina, Botucatu, Brazil; 31. REDONE.br -

Brazilian Registry of Multiple Sclerosis and Neuromyelitis Optica Spectrum Disorders,

Brazil; 32. Irmandade da Santa Casa de Misericórdia de São Paulo, Brazil; 33. Multiple

Sclerosis University Center, Ramos Mejia Hospital - EMA, Argentina; 34. Imperial College

London, United Kingdom; 35. Swansea University, United Kingdom; 36 Mental Health Area,

EMA, Argentina; 37. MS and Demyelinating Diseases. Hospital Británico de Buenos Aires,

EMA, Argentina; 38. Servei de Neurologia-Neuroimmunologia. Centre d'Esclerosi Múltiple

de Catalunya, (Cemcat). Vall d'Hebron Institut de Recerca, Vall d'Hebron Hospital

Universitari. Universitat Autònoma de Barcelona, Spain; 39. Institute of Experimental

Neurology, Ospedale San Raffaele, Italy 
Abstract: 250/250

Body text: 3006/4500

Introduction: $154 / 250$

Tables: 4

Figures: 3

Supplementary tables: 8

References: 19/50

\section{Corresponding author:}

Professor Dr Liesbet M Peeters

Biomedical Research Institute \& Data Science Institute

Hasselt University

Belgium

liesbet.peeters@uhasselt.be

\section{Abstract (250/250)}

Background: People with multiple sclerosis (MS) are a vulnerable group for severe COVID19, particularly those taking immunosuppressive disease-modifying therapies (DMTs). We examined the characteristics of COVID-19 severity in an international sample of people with MS.

Methods: Data from 12 data-sources in 28 countries were aggregated. Demographic and clinical covariates were queried, alongside COVID-19 clinical severity outcomes, hospitalisation, admission to ICU, requiring artificial ventilation, and death. Characteristics of outcomes were assessed in patients with suspected/confirmed COVID-19 using multilevel mixed-effects logistic regression. 
Results: 657 (28.1\%) with suspected and 1,683 (61.9\%) with confirmed COVID-19 were analysed. Older age, progressive MS-phenotype, and higher disability were associated with worse COVID-19 outcomes. Compared to dimethyl fumarate, ocrelizumab and rituximab were associated with hospitalisation $(\mathrm{aOR}=1.56,95 \% \mathrm{CI}=1.01-2.41 ; \mathrm{aOR}=2.43,95 \% \mathrm{CI}=1.48$ 4.02 $)$ and $\mathrm{ICU}$ admission $(\mathrm{aOR}=2.30,95 \% \mathrm{CI}=0.98-5.39$; $\mathrm{aOR}=3.93,95 \% \mathrm{CI}=1.56-9.89)$, though only rituximab was associated with higher risk of artificial ventilation $(\mathrm{aOR}=4.00,95 \% \mathrm{CI}=1.54-10.39)$. Compared to pooled other DMTs, ocrelizumab and rituximab were associated with hospitalisation $(\mathrm{aOR}=1.75,95 \% \mathrm{CI}=1.29-2.38$; $\mathrm{aOR}=2.76,95 \% \mathrm{CI}=1.87-4.07)$ and $\mathrm{ICU}$ admission $(\mathrm{aOR}=2.55,95 \% \mathrm{CI}=1.49-4.36$; $\mathrm{aOR}=4.32,95 \% \mathrm{CI}=2.27-8.23)$ but only rituximab with artificial ventilation $(\mathrm{aOR}=6.15,95 \% \mathrm{CI}=3.09-12.27)$. Compared to natalizumab, ocrelizumab and rituximab were associated with hospitalisation $(\mathrm{aOR}=1.86,95 \% \mathrm{CI}=1.13-3.07 ; \mathrm{aOR}=2.88,95 \% \mathrm{CI}=1.68-4.92)$ and $\mathrm{ICU}$ admission $(\mathrm{aOR}=2.13,95 \% \mathrm{CI}=0.85-5.35 ; \mathrm{aOR}=3.23,95 \% \mathrm{CI}=1.17-8.91)$, but only rituximab with ventilation $(\mathrm{aOR}=5.52,95 \% \mathrm{CI}=1.71-17.84)$. Importantly, associations persisted on restriction to confirmed COVID-19 cases. No associations were observed between DMTs and death.

Conclusions: Using the largest cohort of people with MS and COVID-19 available, we demonstrated consistent associations of rituximab with increased risk of hospitalisation, ICU admission, and requiring artificial ventilation, and ocrelizumab with hospitalisation and ICU admission, suggesting their use may be a risk factor for more severe COVID-19.

\section{Introduction}

Disease-modifying therapies (DMTs) that act by immunomodulatory/immunosuppressive mechanisms are a mainstay of treatment of multiple sclerosis (MS) but can increase infection 
susceptibility ${ }^{1}$. Of current concern is the novel coronavirus, SARS-CoV-2, the cause of Coronavirus Disease of 2019 (COVID-19) ${ }^{2}$. It remains unclear whether people with MS, especially those treated with immunosuppressive DMTs, are more susceptible to more severe COVID-19. Case-series ${ }^{3-6}$ and cohort $^{7-9}$ studies suggest that MS in general does not increase risk for developing severe COVID-19, but comorbidities, age, sex, progressive MSphenotype, and higher disability do ${ }^{7,9}$.

Some studies have also identified associations of certain DMT classes, particularly B-celldepleting DMTs, with COVID-19 severity. However, this varied among studies, potentially due to limited sample size and regional differences in DMT usage ${ }^{7,9}$. Large and geographically inclusive cohorts are required to assess the risk of severe COVID-19 for specific MS DMTs. Accordingly, we established a global data-sharing initiative ${ }^{10}$ to investigate characteristics of COVID-19 severity in people with MS.

\section{Methods}

\section{Data-sources}

This study was approved by the ethical committee of Hasselt University [CME2020/025]. Individual data-sources obtained additional ethics approval as required.

Data from a core questionnaire regarding COVID-19, and relevant patient demographic and neurological information, were reported by treating clinicians, as described previously ${ }^{10}$. Data were entered in three fashions: 1) "Direct entry to central platform"; 2) "Patient-level data sharing via participating registries/cohorts", where MS registries and cohorts are regularly invited to share and upload their COVID-19 core dataset into the central data platform; and 3) 
"Aggregated data sharing via participating registries/cohorts", where some registries do not share patient-level data, but share aggregated results from specific queries. Multidimensional contingency tables from 12 different data-sources were merged and then a combined anonymised dataset was reconstructed.

Data was entered for a given participant once, but information for that participant could be reentered and this then replacing the original record. This thus made for serial iterations of the analysis dataset, which were analysed over time as the dataset expanded, thus allowing for assessment of temporal consistency of observed associations. Previous iterations of the dataset have been presented ${ }^{11}$ but this article describes only the present iteration of the dataset.

\section{Role of the funding source}

The study sponsors had no role in the study design, data collection, analysis, interpretation data, in the writing of the report, or the decision to submit for publication.

\section{Definition of variables}

COVID-19 status was defined as confirmed, based on a positive diagnostic test, or suspected, based on clinician judgement.

Patient age at the time of reporting was categorised into four groups: 0-17, 18-49, 50-69, and $\geq 70$ years; the 0-17 group was excluded $(n=5)$. MS-phenotype was grouped into relapsingremitting MS (RRMS) and progressive MS (SPMS, PPMS). Disability was assessed by the Expanded Disability Status Scale (EDSS) $)^{12}$ or Neurostatus ${ }^{13}$. Disability was dichotomised into 0-6.0 and >6.0. Comorbidities were queried, including cardiovascular disease, hypertension, diabetes, chronic liver disease, kidney disease, other 
neurological/neuromuscular disorder, lung disease, or malignant neoplasia. BMI was categorised as non-obese $(\mathrm{BMI} \leq 30)$ and obese $(\mathrm{BMI}>30)$. Current smoker status was queried as yes or no. Current DMT use was queried, including alemtuzumab, cladribine, dimethyl fumarate, fingolimod, glatiramer-acetate, beta interferons, natalizumab, ocrelizumab, rituximab, siponimod, teriflunomide, or Other DMT. Due to patient numbers <20 among the suspected/confirmed COVID-19 cases, siponimod $(\mathrm{n}=12)$ was aggregated with Other DMT.

\section{Statistical analysis}

Associations with hospitalisation, ICU admission, ventilation, and death were assessed using multilevel mixed-effects logistic regression, random effects grouped by data source, as univariable and adjusted for age, sex, MS-phenotype, and disability. In addition, sensitivityanalyses were completed serially excluding each data-source to assess whether influential data sources underlay associations. Subgroup analyses were also undertaken where data on comorbidities, BMI, and smoking were available, allowing additional adjustment for these covariates. All analyses were complete-case.

For DMTs, individual DMTs were first compared with dimethyl fumarate. Despite leading to lymphopenia in some patients, dimethyl fumarate has not been associated with increased risk of infection ${ }^{14}$, and its biological mechanism of action is unlikely to interfere with the immunological response to SARS-CoV- ${ }^{15}$, while being common in the sample. Next ocrelizumab and rituximab and the untreated were compared with pooled other DMTs. Finally, ocrelizumab and rituximab were evaluated vs natalizumab to assess ascertainment bias, since natalizumab-treated patients present for infusions every 28-42 days, compared to biannual infusions for anti-CD20 DMTs. 
medRxiv preprint doi: https://doi.org/10.1101/2021.02.08.21251316; this version posted February 10, 2021. The copyright holder for this preprint (which was not certified by peer review) is the author/funder, who has granted medRxiv a license to display the preprint in perpetuity.

All rights reserved. No reuse allowed without permission.

Data analyses were carried out using STATA/SE 16.0 (StataCorp, College Station, USA).

\section{Results}

The cohort comprised 2,340 patients, of whom 657 (28.1\%) had suspected COVID-19 and 1,683 (71.9\%) had confirmed COVID-19. Among suspected/confirmed COVID-19 cases, which was the primary analysis dataset, $20.9 \%$ were hospitalised, $5.4 \%$ admitted to ICU, $4.1 \%$ required artificial ventilation, and $3.2 \%$ died. Proportions were slightly higher among confirmed COVID-19 cases (Table 1).

\section{Cohort characteristics}

Data sources were located in: 1) Sweden (n=290); 2) Australia, Belgium, Brasil, Kuwait, Romania, Saudi Arabia, Turkey (n=97); 3) Argentina, Chile, Colombia, Ecuador, Honduras, Mexico ( $\mathrm{n}=159) ; 4)$ Bulgaria ( $\mathrm{n}=3) ; 5)$ Germany, Italy $(\mathrm{n}=45) ; 6)$ Denmark ( $\mathrm{n}=56) ; 7)$ Brasil ( $\mathrm{n}=96) ; 8)$ Australia, Bahamas, Belgium, Czech Republic, Finland, France, Netherlands, New Zealand, Serbia, Spain, UK, USA ( $n=114) ; 9)$ Germany $(n=41) ; 10)$ USA $(n=1,161) ; 11)$ UK $(\mathrm{n}=131) ; 12)$ Spain $(\mathrm{n}=147)$. Sources-2 and 10 had higher proportions with confirmed COVID-19 and Sources-4 and 5 higher with non-suspected COVID-19. Among suspected/confirmed COVID-19 cases, hospitalisation was higher in Source-11 and lower in Sources-2, 4, 5, and 7; ICU admission was higher in Sources-3, 9, and 10, and lower in Sources-2, 4, 7, 9, 11, and 12; ventilation was higher in Sources-3 and 8, and lower in Sources-2, 4, 5, 6, 7, 9, and 11; death was higher in Source-11 and lower in Sources-2, 4, 5, $6,7,8$, and 9. Results were comparable on restriction to confirmed-only COVID-19 (data not shown). 
Compared to dimethyl fumarate, a lower proportion of females were untreated or treated with interferon or ocrelizumab (Table S1). Larger proportions of those aged 50-69 and $\geq 70$ were untreated or treated with ocrelizumab, teriflunomide, or Other DMT. Greater proportions of progressive MS patients were untreated or treated with ocrelizumab, rituximab, or Other DMTs. Of more disabled patients (EDSS $>6$ ), higher proportions were either untreated or treated with ocrelizumab or Other DMTs. Similar results were seen among confirmed-only COVID-19 (data not shown).

\section{COVID-19 severity, by clinical and demographic characteristics}

Demographic and clinical characteristics of hospitalisation and ICU admission (Table 2) and requiring artificial ventilation and death (Table 3) among suspected/confirmed COVID-19 cases were assessed. In multivariable models, female sex showed an inverse trend with risks of hospitalisation and death, while older age was positively associated with hospitalisation and death. Progressive MS-phenotype was associated with higher risk of hospitalisation. Higher EDSS was associated with higher risks of all outcomes. Among confirmed-only COVID-19, most of these associations persisted (Tables S2-S3).

In the subset of data sources with data available, having comorbidities was associated with increased risk of death and obese BMI with increased risks of hospitalisation, ICU admission, and ventilation, while smoking was not associated with any outcomes.

\section{COVID-19 severity, by DMT}

Compared to dimethyl fumarate, rituximab use was associated with greater risks of hospitalisation $(\mathrm{aOR}=2.43)$, ICU admission $(\mathrm{aOR}=3.93)$, and artificial ventilation $(\mathrm{aOR}=4.00$, Table 4). Ocrelizumab showed similar trends for hospitalisation $(\mathrm{aOR}=1.56)$ and ICU 
admission $(\mathrm{aOR}=2.30)$, but not artificial ventilation $(\mathrm{aOR}=1.04)$. No DMTs were associated with death. Untreated patients had increased risk of hospitalisation $(\mathrm{aOR}=1.79)$ but no independent associations with other outcomes were seen. These associations persisted among confirmed-only COVID-19 (Figures 1-3, Table S4).

\section{COVID-19 severity: anti-CD20 DMTs vs pooled other DMTs}

Compared to all other DMTs (Table 4), those using rituximab had higher risks of hospitalisation $(\mathrm{aOR}=2.76)$, $\mathrm{ICU}$ admission $(\mathrm{aOR}=4.32)$, and artificial ventilation $(\mathrm{aOR}=6.15)$. Ocrelizumab showed similar trends for hospitalisation $(\mathrm{aOR}=1.75)$ and $\mathrm{ICU}$ admission $(\mathrm{aOR}=2.55)$ but not ventilation $(\mathrm{aOR}=1.60)$. Neither rituximab or ocrelizumab were associated with risk of death. Untreated patients had increased risks of hospitalisation $(\mathrm{aOR}=2.05)$, ventilation $(\mathrm{aOR}=2.07)$, and death $(\mathrm{aOR}=2.53)$. These results persisted among confirmed-only COVID-19 cases (Table S5).

\section{COVID-19 severity, anti-CD20 DMTs vs natalizumab}

Compared to natalizumab, rituximab was associated with higher risks of hospitalisation $(\mathrm{aOR}=2.88)$, ICU admission $(\mathrm{aOR}=3.23)$, and ventilation $(\mathrm{aOR}=5.52$, Table 4$)$. Ocrelizumab showed similar trends for hospitalisation $(\mathrm{aOR}=1.86)$, but did not reach significance for ICU admission and was not associated with ventilation. Neither rituximab or ocrelizumab was associated with increased risk of death. Results were similar among confirmed-only COVID19 (Table S5).

\section{Mitigating heterogeneity among data sources}

To mitigate the impact of potential heterogeneity among the individual data sources influencing the results, particularly that for source $\mathrm{C} 10$ which comprised nearly half the 
sample, we utilised random-effects logistic regression. However, in addition, serial exclusion analyses were undertaken wherein analyses were run excluding each dataset in turn. These analyses showed no material differences in associations compared to the main analysis (data not shown).

\section{Stratification sensitivity analyses}

To assess whether the associations seen for ocrelizumab and rituximab with outcomes was genuinely a function of the DMTs, rather than the characteristics of patients commonly treated with these medications (older, progressive MS, higher disability), we undertook stratified analyses evaluating associations among persons aged $>70$ years vs $\leq 70$, among RRMS vs progressive, and among EDSS $\leq 6$ vs EDSS $>6$. These analyses showed that associations were actually present in persons of younger age, of RRMS phenotype, and lower EDSS, indicating that the observed associations were a function of the DMT, not underlying risk profile (Tables S6-S8).

\section{Discussion}

In the largest sample of people with MS with suspected and confirmed COVID-19 to date, we demonstrated that the anti-CD20 DMTs rituximab, and to a lesser extent ocrelizumab, were associated with more severe COVID-19. Compared to dimethyl fumarate, pooled other DMTs, and natalizumab, anti-CD20 DMTs were associated with higher risks of hospitalisation and ICU admission, while only rituximab was associated with greater risk of requiring artificial ventilation for each analysis. Comparison to natalizumab is particularly important, suggesting that anti-CD20 associations do not reflect ascertainment bias. Regardless of comparator, rituximab consistently showed stronger associations with 
outcomes than ocrelizumab for hospitalisation and ICU admission, and was solely associated with requiring artificial ventilation. Moreover, DMT associations were not merely driven by older patients, progressive MS-phenotype, or higher disability. We also found that older age, progressive MS-phenotype, and higher disability were over-represented among MS patients with more severe COVID-19. In sub-analyses where data was available, DMT associations were robust to further adjustment for comorbidities, BMI, and smoking status.

Anti-CD20 DMTs, which selectively deplete circulating B-lymphocytes, alemtuzumab and cladribine which act through broader immunosuppressive mechanisms, and fingolimod, which sequesters lymphocytes from circulation, are highly effective MS treatments, but can increase infection risk ${ }^{1,16}$. This has raised concern during the COVID-19 pandemic and national studies have investigated risk factors for severe COVID-19 disease in people with MS. In the French COVISEP study ${ }^{7}$ of 347 MS patients (42.1\% confirmed COVID-19), older age, progressive MS-phenotype, higher disability, and comorbidities were associated with COVID-19 severity. In addition, pooled DMTs with moderate/high risk of systemic infection (fingolimod, ocrelizumab, rituximab, cladribine, alemtuzumab) were associated with 4.2times higher COVID-19 severity score than DMTs with no systemic infection risk (interferon- $\square$, glatiramer-acetate). This amalgamation of DMTs is a limitation since, while comparable in terms of their infection risk, these DMTs have markedly different modes of action, especially in relation to the immunological response to SARS-CoV-2 ${ }^{15}$. More recently, the Italian MuSC-19 national registry study of 593 suspected and 191 confirmed COVID-19 cases, found anti-CD20 DMT use was associated with 2.6-times greater risk of severe COVID-19 compared to dimethyl fumarate, adjusted for region, age, sex, MSphenotype, and recent methylprednisolone use ${ }^{9}$. 
Untreated patients showed consistent positive trends towards associations with hospitalisation, ICU admission, and requiring ventilation, albeit attenuating on adjustment. This is in keeping with prior results. Louapre and colleagues found higher frequencies of severe COVID-19 among the untreated vs treated (46.0\% vs $15.5 \%)$, though this difference did not persist on adjustment ${ }^{7}$. Sormani and colleagues compared untreated to dimethyl fumarate-treated, finding they were 2.83-times more likely to have severe COVID-19, though this disappeared on adjustment $(\mathrm{aOR}=1.04)^{9}$. The lack of independence of the untreated associations here and previously likely reflects the untreated comprising to variable degree people with more benign MS course or other reasons to not use DMTs, so adjustment for MS-phenotype and disability largely captures differences in COVID-19 severity.

Of interest are the differences in the magnitudes of associations seen for ocrelizumab and rituximab, since both bind the same CD20 epitope on the outer loop of the protein, albeit in slightly different fashions ${ }^{17,18}$. In comparison to dimethyl fumarate, to pooled other DMTs, and to natalizumab, rituximab consistently showed stronger associations with outcomes than ocrelizumab. Importantly, in analyses stratifying associations of DMT exposure with COVID19 severity by age, MS-phenotype, and EDSS, there was no evidence that the antiCD20 DMT associations merely reflects patients with underlying risk factors being disposed to use these treatments. The differences seen, both in magnitudes of associations with hospitalisation and ICU admission and the lack of association with ventilation, are puzzling. This weaker magnitude for ocrelizumab has been seen in prior iterations of the analysis but also in those prior iterations ocrelizumab was significantly associated with ventilation as well as hospitalisation and ICU admission, albeit of weaker magnitude ${ }^{11}$. That ocrelizumab was no longer associated in this iteration of the data may reflect changes in medical practice for COVID-19 treatment, including the introduction of more effective treatments that reduce the 
need for patients to require artificial ventilation. The weaker magnitudes of associations may reflect ocrelizumab's slightly lower affinity to CD20 or possibly their different provenance, rituximab being a chimeric $\operatorname{IgG}$ while ocrelizumab is humanised ${ }^{17,18}$. Also, the mode of Bcell elimination differs, with ocrelizumab using more antibody and less complementmediated cytotoxicity compared to rituximab ${ }^{19}$. Alternatively, this difference may represent unmeasured confounding as the dataset, while large, was limited in the number of characteristics assessed, so potentially relevant factors like socioeconomic status and access to care or factors impacting on respiratory health could not be assessed. That said, our results are broadly in line with those seen in other studies ${ }^{7,9}$, providing external consistency. This preliminary observation is worth exploring in laboratory studies.

That anti-CD20 DMTs were not associated with death conflicts with the results seen for the other outcomes, as well as with the MuSC-19 study which found a positive trend between anti-CD20 DMTs and death. The issue may lie in ascertainment bias, with fewer of the older patients included in our sample: we had only $9.1 \%$ of confirmed COVID-19 cases over 60 years old, vs $17.7 \%$ in the MuSC-19 cohort $^{9}$. The potential impacts of these DMTs on death due to COVID-19 should be further explored.

\section{Limitations}

In contrast to prior clinic-based studies, our cohort focused on a pre-defined limited set of demographic and clinical characteristics ${ }^{10}$. Thus, we could not assess other clinical features, particularly prior MS clinical course and DMT use, paraclinical information such as radiological burden of MS, or the nuanced details of COVID-19 onset and evolution. Another limitation of our data is that they likely comprise greater proportions of severe cases requiring medical attention. One particular element lacking in our data is treatment duration or duration 
since treatment, since these both may have bearing on the degree of B-cell depletion and thence on COVID-19 severity. This data was included in the core questionnaire but the level of missingness was too high to be a component of analyses.

Heterogeneity in the definitions of exposure and outcomes and in patient inclusion among the data-sources is a known problem in combining multiple data-sources. Related to this are the differences in protocols for hospital and ICU admission and initiation of artificial ventilation between hospitals. To ensure that our results were not being driven by single influential datasources, we undertook all analyses using random-effects logistic regression, as well as serialexclusion sensitivity analyses. These analyses showed that, while there was some variation in the magnitudes and significance of associations, trends tracked as seen for the whole cohort, indicating that the results were not driven by a specific data-source.

Another issue lies in the anonymous nature of the data entry, such that patients may be entered more than once in different data-sources. We are unable to account for whether participants already participated or had their data entered in another study as there is no identifying information to assess this, nor any query of prior participation in the survey.

Another issue is the comparator used for individual DMTs. We initially planned to compare to glatiramer acetate given its absence of impact on infection risk; however, infrequency of outcomes among these patients precluded its being the comparator. Interferon-beta and teriflunomide were potential comparators but their potential impacts on infection immune response argued against this. Dimethyl fumarate was identified as a suitable comparator, being common in the sample and was also that used for the MuSC-19 study ${ }^{9}$. The untreated 
were not regarded as an appropriate primary comparator because these patients differed markedly from the rest of the cohort in age, disability, and MS-phenotype.

Another issue is the nature of the data aggregation, with some data sources providing individual patient-level data but others only tabulations of discrete categorical terms. Thus, we were obliged to use three-level categories of age and two-level EDSS, rather than more exact values of each. That said, these levels are generally aligned with the levels of each associated with increased COVID-19 severity.

Another issue is the definition of outcome values. Where these values were missing, we have left them as such, rather than inferring for instance that patients who were not hospitalised were also not admitted to ICU or required artificial ventilation. This was a conservative allocation that increased the proportions missing for such parameters, rather than coding them to null values, but analyses coding such to null values made little impact on results (data not shown).

\section{Conclusions}

In the largest population yet studied, we have shown that MS patients treated with anti-CD20 DMTs, rituximab and ocrelizumab, are at higher risk of more severe COVID-19 compared to those treated with dimethyl fumarate, to pooled other DMTs, and to natalizumab. This risk is additional to the risk associated with demographic and clinical characteristics. These results agree with smaller cohort studies and suggest that the risk-vs-benefit of continued or new exposure to CD20-depleting treatment strategies compared to other DMTs needs to be considered in the context of the ongoing COVID-19 pandemic. 
Figure 1. The risk of hospitalisation by DMT among suspected/confirmed (solid line) and confirmed-only (dashed line) cases. DMTs compared to dimethyl fumarate, adjusted for age, sex, MS-phenotype, and EDSS. Note: Other DMTs also includes siponimod. $*=p<0.05, * *$ $=p<0.001$.

Figure 2: The risk of ICU admission by DMT, among suspected/confirmed (solid line) and confirmed-only (dashed line) cases. DMTs were compared to dimethyl fumarate, adjusted for age, sex, MS-phenotype, and EDSS. Note: Other DMTs also includes siponimod. $*=p<0.05$. Note: null set denotes analyses which could not be undertaken due to no events occurring in the exposed group.

Figure 3: The risk of artificial ventilation by DMT, among suspected/confirmed (solid line) and confirmed-only (dashed line) cases. DMTs were compared to dimethyl fumarate, adjusted for age, sex, MS-phenotype, and EDSS. Note: Other DMTs also includes siponimod. $*=p<0.05$. Note: null set denotes analyses which could not be undertaken due to no events occurring in the exposed group. 


\section{Funding}

The author(s) disclosed receipt of the following financial support for the research, authorship, and/or publication of this article: The operational costs linked to this study are funded by the Multiple Sclerosis International Federation (MSIF) and the Multiple Sclerosis Data Alliance (MSDA), acting under the umbrella of the European Charcot Foundation (ECF). The MSDA receives income from a range of corporate sponsors, recently including Biogen, BristolMyers Squibb (formerly Celgene), Canopy Growth Corporation, Genzyme, Icometrix, Merck, Mylan, Novartis, QMENTA, Quanterix and Roche. MSIF receives income from a range of corporate sponsors, recently including Biogen, Bristol-Myers Squibb (formerly Celgene), Genzyme, Med-Day, Merck, Mylan, Novartis and Roche. This work was supported by the Flemish Government under the Onderzoeksprogramma Artificiële Intelligentie (AI) Vlaanderen programme and the Research Foundation Fladers (FWO) for ELIXIR Belgium Flanders (FWO) for ELIXIR Belgium. The central platform was provided by QMENTA and the computational resources used in this work were provided by Amazon.

\section{Declaration of interests}

TK has served on scientific advisory boards for Roche, Sanofi-Genzyme, Novartis, Merck and Biogen, steering committee for Brain Atrophy Initiative by Sanofi-Genzyme, received conference travel support and/or speaker honoraria from WebMD Global, Novartis, Biogen, Sanofi-Genzyme, Teva, BioCSL and Merck and received research support from Biogen. NR \& CW have no personal pecuniary interests to disclose, other than being an employee of MSIF, which receives income from a range of corporate sponsors, recently including: Biogen, BristolMyersSquibb (formerly Celgene), Genzyme, Med-Day, Merck, Mylan, Novartis, Roche. JH has received honoraria for serving on advisory boards for Biogen, Celgene, Sanofi-Genzyme, Merck KGaA, Novartis and Sandoz and speaker's fees from 
Biogen, Novartis, Merck KGaA, Teva and Sanofi-Genzyme, has served as principal investigator for projects, or received unrestricted research support from Biogen, Celgene, Merck KGaA, Novartis, Roche and Sanofi-Genzyme, and his MS research was funded by the Swedish Research Council and the Swedish Brain foundation. GE has received consulting/speaking fees and research support from Bayer, Novartis, Teva, Sanofi Genzyme, Merck Serono, Biogen Idec, and Roche. TS has served on scientific advisory boards for Biogen. RMcB \& HS, work for the Accelerated Cure Project for MS (ACP), which has received grants, collaboration funding, payments for use of assets, or in-kind contributions from the following companies: EMD Serono, Sanofi/Genzyme, Biogen, Genentech, AbbVie, Octave, GlycoMinds, Pfizer, MedDay, AstraZeneca, Teva, Mallinckrodt, MSDx, Regeneron Genetics Center, BC Platforms, and Celgene. ACP has also received funding from the Patient-Centered Outcomes Research Institute (PCORI) and the National MS Society (NMSS). AG has received research support from Novartis. RMcB. has received consulting payments from EMD Serono, which have been donated to ACP. AB has received consulting fees from and is an advisory board/speaker/other activities for NeuroTransData, and has worked on project management/clinical studies for and received travel expenses from Novartis and Servier. AS has no personal pecuniary interests to disclose, other than being the lead of the German MS-Registry, which receives (project) funding from a range of public and corporate sponsors, recently including The German Innovation Fund (G-BA), The German MS Trust, Biogen, German MS Society, Celgene (BMS), Merck, Novartis, Roche, and Sanofi. RM has received no personal funding from any sources, but works for the UK MS Register which is funded by the UK MS Society and has received funding for specific projects from Novartis, Sanofi-Genzyme and Merck KGaA. RJF has received personal consulting fees from Actelion, Biogen, Celgene, EMD Serono, Genentech, Immunic, Novartis, Sanofi, Teva, and TG Therapeutics, and has served on advisory committees for 
Actelion, Biogen, Immunic, and Novartis, and received clinical trial contract and research grant funding from Biogen and Novartis. AvdW has received honoraria and unrestricted research funding from Novartis, Biogen, Roche, Merck and Sanofi. HB's institution receives compensation for Advisory Board, Steering Committee and Educational activities from Biogen, Roche, Merck, and Novartis. His institution receives research support from Roche, Novartis, Biogen, NHMRC and MRFF Australia, MS Research Australia and the Trish MS Foundation. He receives personal compensation from Oxford HPF for serving on the steering group of MS Brain Health. RA-R received honoraria as a speaker and for serving on scientific advisory boards from Bayer, Biogen, GSK, Merck, Novartis, Roche and SanofiGenzyme. JIR has received honoraria from Novartis as a scientific advisor, and has received travel grants and attended courses and conferences on behalf of Merck-Serono Argentina, Novartis Argentina. GSdO has received honoraria for lecturing and support for congress participation from Biogen, Merck, Novartis, Sanofi/Genzyme, EMS and Roche. MM has served on scientific advisory board for Biogen, Sanofi, Roche, Novartis, Merck, Abbvie, has received honoraria for lecturing from Biogen, Merck, Novartis, Sanofi, Genzyme, and has received research support and support for congress participation from Biogen, Genzyme, Roche, Merck, Novartis. RA has received honoraria from Novartis as a scientific advisor, travel grants and attended courses and conferences on behalf of Merck-Serono Argentina, Biogen Argentina, Genzyme Argentina, Roche Argentina and Novartis Argentina. RN has received honoraria from Novartis, Roche and Biogen for advisory boards. AZ has received travel expenses for scientific meetings from Biogen, Novartis, and Genzyme, speaking honoraria from Eisai, and a study grant from Novartis. GA has received compensation for consulting services or participation in advisory boards from Sanofi, Merck and Roche; research support from Novartis; travel expenses for scientific meetings from Novartis, Roche, Stendhal, and ECTRIMS; speaking honoraria from Sanofi and Merck; and is a member of the 
International Women in Multiple Sclerosis (iWiMS) network executive committee. GC has received consulting and speaking fees from Novartis, Teva Pharmaceutical Industries Ltd, Teva Italia Srl, Sanofi Genzyme, Genzyme Corporation, Genzyme Europe, Merck KGgA, Merck Serono SpA, Celgene Group, Biogen Idec, Biogen Italia Srl, F. Hoffman-La Roche, Roche SpA, Almirall SpA, Forward Pharma, Medday and Excemed. LMP has no personal pecuniary interests to disclose, other than being the chair of The MS Data Alliance (MSDA), which receives income from a range of corporate sponsors, recently including Biogen, BristolMyersSquibb (formerly Celgene), Canopy Growth Corporation, Genzyme, Icometrix, Merck, Mylan, Novartis, QMENTA, Quanterix, Roche. SSY, EDB, YM, LG, TP, CG, NL, AP, AA, LEF, SB, AS, SO, IvDM, NN, RI, AED, DG, MFM, JB, AF, and AC have no conflicts of interests to disclose.

\section{References}

1. Luna G, Alping P, Burman J, et al. Infection Risks Among Patients With Multiple Sclerosis Treated With Fingolimod, Natalizumab, Rituximab, and Injectable Therapies. JAMA neurology $2019 ; 77$.

2. Khan S, Siddique R, Shereen MA, et al. The emergence of a novel coronavirus (SARS-CoV2), their biology and therapeutic options. Journal of clinical microbiology 2020.

3. Montero-Escribano P, Matías-Guiu J, Gómez-Iglesias P, Porta-Etessam J, Pytel V, MatiasGuiu JA. Anti-CD20 and COVID-19 in multiple sclerosis and related disorders: A case series of 60 patients from Madrid, Spain. Multiple sclerosis and related disorders 2020;42:102185.

4. Loonstra FC, Hoitsma E, van Kempen ZL, Killestein J, Mostert JP. COVID-19 in multiple sclerosis: The Dutch experience. Multiple sclerosis (Houndmills, Basingstoke, England) 2020:1352458520942198.

5. Fan M, Qiu W, Bu B, et al. Risk of COVID-19 infection in MS and neuromyelitis optica spectrum disorders. Neurology(R) neuroimmunology \& neuroinflammation 2020;7.

6. Safavi F, Nourbakhsh B, Azimi AR. B-cell depleting therapies may affect susceptibility to acute respiratory illness among patients with multiple sclerosis during the early COVID-19 epidemic in Iran. Multiple sclerosis and related disorders 2020;43:102195.

7. Louapre C, Collongues N, Stankoff B, et al. Clinical Characteristics and Outcomes in Patients With Coronavirus Disease 2019 and Multiple Sclerosis. JAMA neurology 2020.

8. Evangelou N, Garjani A, dasNair R, et al. Self-diagnosed COVID-19 in people with multiple sclerosis: a community-based cohort of the UK MS Register. Journal of neurology, neurosurgery, and psychiatry 2020.

9. Sormani MP, De Rossi N, Schiavetti I, et al. Disease modifying therapies and Covid-19 severity in Multiple Sclerosis. Annals of neurology 2021.

10. Peeters LM, Parciak T, Walton C, et al. COVID-19 in people with multiple sclerosis: A global data sharing initiative. Multiple sclerosis (Houndmills, Basingstoke, England)

2020:1352458520941485. 
11. Simpson-Yap S, De Brouwer E, Kalincik T, et al. SS02.04 - First results of the COVID-19 in MS Global Data Sharing Initiative suggest anti-CD20 DMTs are associated with worse COVID-19 outcomes. MSVirtual 2020; 2020.

12. Kurtzke JF. Rating neurologic impairment in multiple sclerosis: an expanded disability status scale (EDSS). Neurology 1983;33:1444-1452.

13. D'Souza M, Yaldizli Ö, John R, et al. Neurostatus e-Scoring improves consistency of Expanded Disability Status Scale assessments: A proof of concept study. Multiple sclerosis (Houndmills, Basingstoke, England) 2017;23:597-603.

14. Mehta D, Miller C, Arnold DL, et al. Effect of dimethyl fumarate on lymphocytes in RRMS: Implications for clinical practice. Neurology 2019;92:e1724-e1738.

15. Baker D, Amor S, Kang AS, Schmierer K, Giovannoni G. The underpinning biology relating to multiple sclerosis disease modifying treatments during the COVID-19 pandemic. Multiple sclerosis and related disorders 2020;43:102174.

16. Wijnands JMA, Zhu F, Kingwell E, et al. Disease-modifying drugs for multiple sclerosis and infection risk: a cohort study. Journal of neurology, neurosurgery, and psychiatry 2018;89:1050-1056. 17. Myhr KM, Torkildsen $\emptyset$, Lossius A, B $\varnothing$ L, Holmøy T. B cell depletion in the treatment of multiple sclerosis. Expert opinion on biological therapy 2019;19:261-271.

18. Klein C, Lammens A, Schäfer W, et al. Epitope interactions of monoclonal antibodies targeting CD20 and their relationship to functional properties. mAbs 2013;5:22-33.

19. Gelfand JM, Cree BAC, Hauser SL. Ocrelizumab and Other CD20(+) B-Cell-Depleting Therapies in Multiple Sclerosis. Neurotherapeutics : the journal of the American Society for Experimental NeuroTherapeutics 2017;14:835-841. 
$\begin{array}{rrrr}i & & \\ \vdots & & & \\ i & 1.561 .62\end{array}$ 


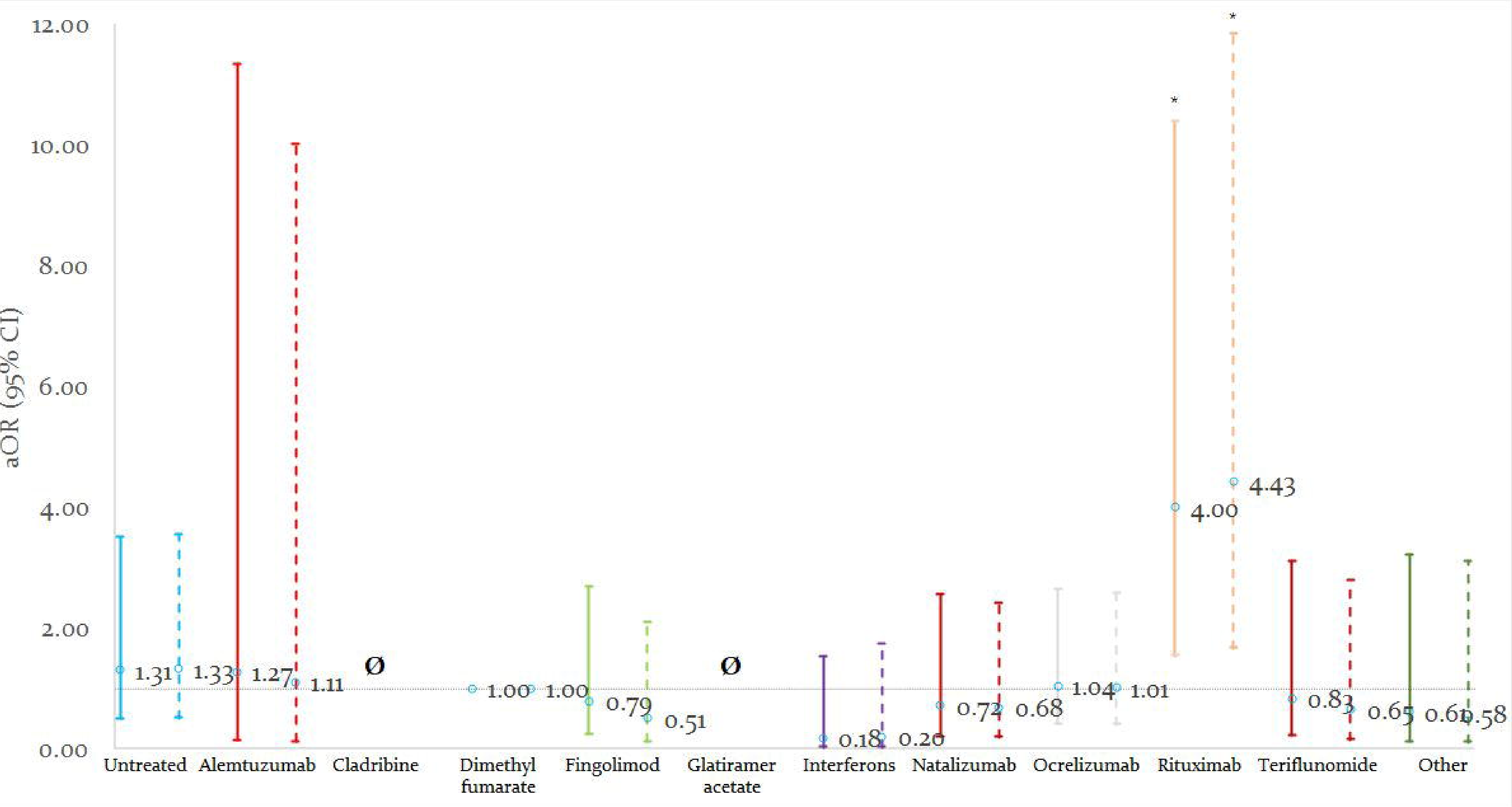




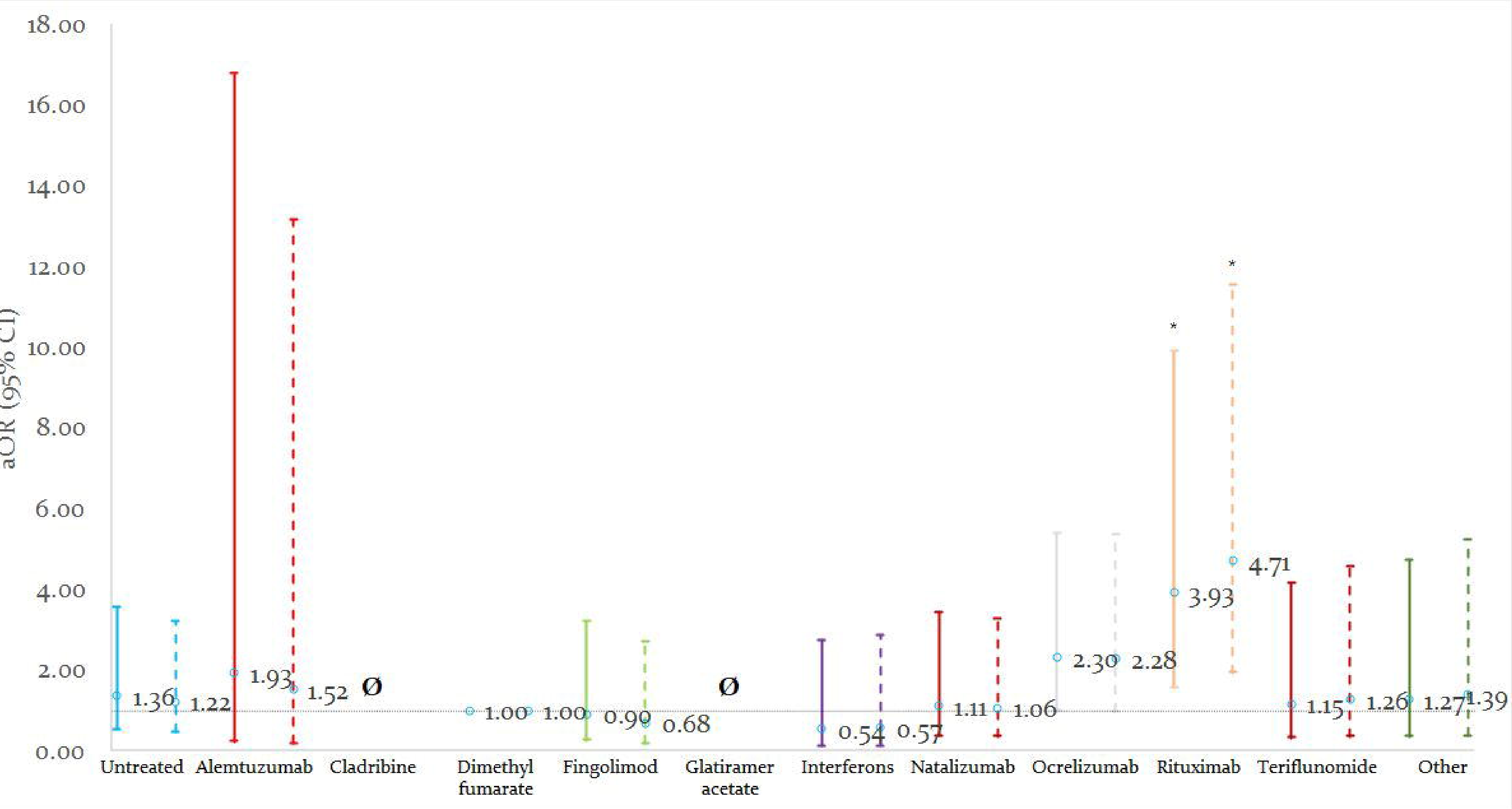


Table 1. Cohort characteristics.

\begin{tabular}{|c|c|c|}
\hline & $\begin{array}{c}\text { Suspected \& } \\
\text { confirmed }(n=2340)\end{array}$ & $\begin{array}{c}\text { Confirmed } \\
(\mathrm{n}=1683)\end{array}$ \\
\hline \multicolumn{3}{|c|}{ COVID-19 status } \\
\hline Suspected & 657 (28.1\%) & $0(0.0 \%)$ \\
\hline Confirmed & $1683(71.9 \%)$ & $1683(100.0 \%)$ \\
\hline \multicolumn{3}{|c|}{ Hospitalisation } \\
\hline No & 1705 (72.9\%) & $1144(68.0 \%)$ \\
\hline Yes & 489 (20.9\%) & 453 (26.9\%) \\
\hline Missing & $146(6.2 \%)$ & $86(5.1 \%)$ \\
\hline \multicolumn{3}{|c|}{ ICU admission } \\
\hline No & $1839(78.6 \%)$ & 1355 (80.5\%) \\
\hline Yes & 127 (5.4\%) & $122(7.2 \%)$ \\
\hline Missing & $338(14.4 \%)$ & 199 (11.8\%) \\
\hline \multicolumn{3}{|l|}{ Ventilation } \\
\hline No & $1755(75.0 \%)$ & $1316(78.2 \%)$ \\
\hline Yes & 97 (4.1\%) & $91(5.4 \%)$ \\
\hline Missing & $452(19.3 \%)$ & $269(16.0 \%)$ \\
\hline \multicolumn{3}{|l|}{ Death } \\
\hline No & $2053(89.1 \%)$ & $1491(88.6 \%)$ \\
\hline Yes & $73(3.2 \%)$ & 65 (3.9\%) \\
\hline Missing & $178(7.7 \%)$ & $120(7.1 \%)$ \\
\hline \multicolumn{3}{|l|}{ Sex } \\
\hline Male & $637(27.2 \%)$ & 469 (27.9\%) \\
\hline Female & $1702(72.7 \%)$ & $1213(72.1 \%)$ \\
\hline Missing & $1(0.0 \%)$ & $1(0.1 \%)$ \\
\hline \multicolumn{3}{|l|}{ Age } \\
\hline $18-<50$ & 1505 (64.3\%) & $1032(61.3 \%)$ \\
\hline
\end{tabular}




\begin{tabular}{|l|c|c|}
\hline $50-<70$ & $740(31.6 \%)$ & $571(33.9 \%)$ \\
\hline $70+$ & $83(3.5 \%)$ & $72(4.3 \%)$ \\
\hline Missing & $12(0.5 \%)$ & $8(0.5 \%)$ \\
\hline EDSS & & \\
\hline $0-6$ & $1837(78.5 \%)$ & $1275(75.8 \%)$ \\
\hline$>6$ & $438(18.7 \%)$ & $368(21.9 \%)$ \\
\hline Missing & $65(2.8 \%)$ & $40(2.4 \%)$ \\
\hline Has comorbidities & & \\
\hline No & $984(43.5 \%)$ & $745(45.5 \%)$ \\
\hline Yes & $920(40.7 \%)$ & $707(43.2 \%)$ \\
\hline Missing & $357(15.8 \%)$ & $184(11.3 \%)$ \\
\hline BMI & & \\
\hline No & $820(36.3 \%)$ & $656(40.1 \%)$ \\
\hline Yes & $437(19.3 \%)$ & $376(23.0 \%)$ \\
\hline Missing & $1004(44.4 \%)$ & $604(36.9 \%)$ \\
\hline Current smoker & & \\
\hline No & $1627(72.0 \%)$ & $1266(77.4 \%)$ \\
\hline Yes & $166(7.3 \%)$ & $115(7.0 \%)$ \\
\hline Missing & $468(20.7 \%)$ & $255(15.6 \%)$ \\
\hline DMT & & \\
\hline Untreated & $284(12.1 \%)$ & $231(13.7 \%)$ \\
\hline Alemtuzumab & $31(1.3 \%)$ & $26(1.5 \%)$ \\
\hline Cladribine & $29(1.2 \%)$ & $17(1.0 \%)$ \\
\hline Dimethyl fumarate & $275(11.8 \%)$ & $199(11.8 \%)$ \\
\hline Fingolimod & $200(8.5 \%)$ & $143(8.5 \%)$ \\
\hline Glatiramer acetate & $87(3.7 \%)$ & $70(4.2 \%)$ \\
\hline Interferon & $124(5.3 \%)$ & $85(5.1 \%)$ \\
\hline Natalizumab & $221(9.4 \%)$ & $164(9.7 \%)$ \\
\hline Ocrelizumab & $471(20.1 \%)$ & $365(21.7 \%)$ \\
\hline & & \\
\hline & & \\
\hline
\end{tabular}




\begin{tabular}{|l|c|r|}
\hline Rituximab & $258(11.0 \%)$ & $142(8.4 \%)$ \\
\hline Teriflunomide & $97(4.1 \%)$ & $75(4.5 \%)$ \\
\hline Other DMT & $70(3.0 \%)$ & $47(2.8 \%)$ \\
\hline Missing & $193(8.2 \%)$ & $119(7.1 \%)$ \\
\hline Abre
\end{tabular}

Abbreviation: COVID-19 = Coronavirus Disease of 2019; DMT

= disease-modifying therapy, EDSS $=$ Expanded Disability

Status Scale; ICU = Intensive care unit; MS = multiple sclerosis;

RRMS = relapsing-remitting multiple sclerosis. 
Table 2. Demographic and clinical characteristics of hospitalisation \& ICU admission, suspected+confirmed COVID-19.

\begin{tabular}{|c|c|c|c|c|c|c|}
\hline & Hospitalisation & & & ICU admission & & \\
\hline & $\mathrm{n}(\%)$ & OR (95\% CI) & $\mathrm{aOR}(95 \% \mathrm{CI})^{\mathrm{a}}$ & $\mathrm{n}(\%)$ & OR (95\% CI) & $\mathrm{aOR}(95 \% \mathrm{CI})^{\mathrm{a}}$ \\
\hline \multicolumn{7}{|l|}{ Sex } \\
\hline Male & $160 / 522(30.7 \%)$ & 1.00 [Ref] & 1.00 [Ref] & $33 / 463(7.1 \%)$ & 1.00 [Ref] & 1.00 [Ref] \\
\hline \multirow[t]{2}{*}{ Female } & 269/1433 (18.8\%) & $0.53(0.42,0.66)$ & $0.62(0.48,0.79)$ & 73/1304 (5.6\%) & $0.76(0.50,1.17)$ & $0.96(0.62,1.49)$ \\
\hline & & $\mathrm{p}<0.001$ & $\mathrm{p}<0.001$ & & $\mathrm{p}=0.21$ & 0.85 \\
\hline \multicolumn{7}{|l|}{ Age } \\
\hline $18-<50$ & 188/1277 (14.7\%) & 1.00 [Ref] & 1.00 [Ref] & $41 / 1160(3.5 \%)$ & 1.00 [Ref] & 1.00 [Ref] \\
\hline $50-<70$ & 208/614 (33.9\%) & $2.90(2.30,3.66)$ & $2.03(1.57,2.61)$ & $59 / 551(10.7 \%)$ & $3.24(2.14,4.91)$ & $2.26(1.44,3.57)$ \\
\hline \multirow[t]{2}{*}{$70+$} & $33 / 64(51.6 \%)$ & $5.60(3.31,9.45)$ & $2.01(1.12,3.62)$ & $6 / 56(10.7 \%)$ & $3.31(1.33,8.21)$ & $1.36(0.51,3.65)$ \\
\hline & & $\mathrm{p}<0.001$ & $p=0.019$ & & $\mathrm{p}<0.001$ & 0.54 \\
\hline \multicolumn{7}{|l|}{ MS phenotype } \\
\hline RRMS & $261 / 1600(16.3 \%)$ & 1.00 [Ref] & 1.00 [Ref] & $63 / 1452(4.3 \%)$ & 1.00 [Ref] & 1.00 [Ref] \\
\hline \multirow[t]{2}{*}{ Progressive } & 168/355 (47.3\%) & $4.42(3.43,5.68)$ & $1.68(1.20,2.37)$ & 43/315 (13.7\%) & $3.65(2.41,5.54)$ & $1.68(0.95,2.98)$ \\
\hline & & $\mathbf{p}<\mathbf{0 . 0 0 1}$ & $p=0.003$ & & $\mathrm{p}<\mathbf{0 . 0 0 1}$ & $\mathrm{p}=0.077$ \\
\hline \multicolumn{7}{|l|}{ EDSS } \\
\hline $0-6$ & 252/1594 (15.8\%) & 1.00 [Ref] & 1.00 [Ref] & $60 / 1437(4.2 \%)$ & 1.00 [Ref] & 1.00 [Ref] \\
\hline \multirow[t]{2}{*}{$>6$} & 177/361 (49.0\%) & $5.07(3.92,6.55)$ & $2.79(2.01,3.89)$ & 46/330 (13.9\%) & $3.72(2.46,5.62)$ & $2.11(1.21,3.67)$ \\
\hline & & $\mathrm{p}<0.001$ & $\mathrm{p}<0.001$ & & $\mathbf{p}<\mathbf{0 . 0 0 1}$ & $p=0.008$ \\
\hline \multicolumn{7}{|l|}{$\begin{array}{l}\text { Has } \\
\text { comorbidities }\end{array}$} \\
\hline No & 94/567 (16.6\%) & 1.00 [Ref] & 1.00 [Ref] & $24 / 551(4.4 \%)$ & 1.00 [Ref] & 1.00 [Ref] \\
\hline \multirow[t]{2}{*}{ Yes } & 130/439 (29.6\%) & $2.31(1.62,3.28)$ & $1.56(1.06,2.30)$ & 36/408 (8.8\%) & $1.91(1.06,3.44)$ & $1.17(0.62,2.19)$ \\
\hline & & $\mathrm{p}<0.001$ & $p=0.026$ & & $\mathrm{p}=0.031$ & $\mathrm{p}=0.64$ \\
\hline \multicolumn{7}{|l|}{ BMI } \\
\hline$<30$ & 129/653 (19.8\%) & 1.00 [Ref] & 1.00 [Ref] & $21 / 620$ (3.4\%) & 1.00 [Ref] & 1.00 [Ref] \\
\hline$\geq 30$ & 95/353 (26.9\%) & $1.22(0.87,1.73)$ & $1.52(1.04,2.22)$ & 39/339 (11.5\%) & $2.42(1.33,4.41)$ & $3.12(1.67,5.84)$ \\
\hline
\end{tabular}




\begin{tabular}{|c|c|c|c|c|c|c|}
\hline & & $\mathrm{p}=0.26$ & $p=0.031$ & & $p=0.004$ & $\mathbf{p}<0.001$ \\
\hline \multicolumn{7}{|l|}{$\begin{array}{l}\text { Current } \\
\text { smoker }\end{array}$} \\
\hline No & 205/901 (22.8\%) & 1.00 [Ref] & 1.00 [Ref] & $58 / 859(6.8 \%)$ & 1.00 [Ref] & 1.00 [Ref] \\
\hline \multirow[t]{2}{*}{ Yes } & 19/105 (18.1\%) & $0.67(0.35,1.28)$ & $0.80(0.41,1.55)$ & $2 / 100(2.0 \%)$ & $0.39(0.09,1.63)$ & $0.41(0.09,1.78)$ \\
\hline & & $\mathrm{p}=0.22$ & $\mathrm{p}=0.51$ & & $\mathrm{p}=0.20$ & $\mathrm{p}=0.23$ \\
\hline
\end{tabular}

Analysis by multilevel mixed-effects logistic regression, estimating OR (95\% CI). ${ }^{\mathrm{a}}$ Multivariable models adjusted for age, sex, MS phenotype, and EDSS. Abbreviations: EDSS = Expanded Disability Status Scale; ICU = Intensive Care Unit; MS = multiple sclerosis; OR = odds ratio; RRMS = relapsing-remitting multiple sclerosis. Results in boldface denote statistical significance $(\mathrm{p}<0.05)$. 
Table 3. Demographic and clinical characteristics of ventilation \& death, suspected+confirmed COVID-19.

\begin{tabular}{|c|c|c|c|c|c|c|}
\hline & Ventilation & & & Death & & \\
\hline & n (\%) & OR (95\% CI) & aOR $(95 \% \text { CI })^{\mathrm{a}}$ & $\mathrm{n}(\%)$ & OR (95\% CI) & $\mathrm{aOR}(95 \% \mathrm{CI})^{\mathrm{a}}$ \\
\hline \multicolumn{7}{|l|}{ Sex } \\
\hline Male & $26 / 425$ (6.1\%) & 1.00 [Ref] & 1.00 [Ref] & $31 / 511(6.1 \%)$ & 1.00 [Ref] & 1.00 [Ref] \\
\hline \multirow[t]{2}{*}{ Female } & $58 / 1241(4.7 \%)$ & $0.78(0.48,1.26)$ & $0.96(0.58,1.58)$ & $32 / 1,386(2.3 \%)$ & $0.37(0.22,0.61)$ & $0.52(0.30,0.89)$ \\
\hline & & $\mathrm{p}=0.30$ & 0.87 & & $\mathrm{p}<\mathbf{0 . 0 0 1}$ & $p=0.017$ \\
\hline \multicolumn{7}{|l|}{ Age } \\
\hline $18-<50$ & $34 / 1104(3.1 \%)$ & 1.00 [Ref] & 1.00 [Ref] & $11 / 1,229(0.9 \%)$ & 1.00 [Ref] & 1.00 [Ref] \\
\hline $50-<70$ & $44 / 512(8.6 \%)$ & $3.28(2.04,5.27)$ & $2.41(1.44,4.04)$ & 42/606 (6.9\%) & $7.77(3.95,15.30)$ & $3.54(1.71,7.32)$ \\
\hline \multirow[t]{2}{*}{$70+$} & $6 / 50(12.0 \%)$ & $5.13(1.98,13.29)$ & $2.21(0.77,6.29)$ & 10/62 (16.1\%) & $17.51(6.93,44.25)$ & $3.73(1.37,10.13)$ \\
\hline & & $\mathrm{p}<0.001$ & 0.14 & & $p<0.001$ & $p=0.003$ \\
\hline \multicolumn{7}{|l|}{ MS phenotype } \\
\hline RRMS & $53 / 1379(3.8 \%)$ & 1.00 [Ref] & 1.00 [Ref] & $20 / 1,548(1.3 \%)$ & 1.00 [Ref] & 1.00 [Ref] \\
\hline \multirow[t]{2}{*}{ Progressive } & $31 / 287(10.8 \%)$ & $3.26(2.02,5.27)$ & $1.24(0.66,2.36)$ & 43/349 (12.3\%) & $10.06(5.78,17.52)$ & $1.56(0.77,3.15)$ \\
\hline & & $\mathbf{p}<\mathbf{0 . 0 0 1}$ & 0.50 & & $\mathrm{p}<0.001$ & $\mathrm{p}=0.21$ \\
\hline \multicolumn{7}{|l|}{ EDSS } \\
\hline $0-6$ & 49/1363 (3.6\%) & 1.00 [Ref] & 1.00 [Ref] & $12 / 1,527(0.8 \%)$ & 1.00 [Ref] & 1.00 [Ref] \\
\hline \multirow[t]{2}{*}{$>6$} & 35/303 (11.6\%) & $4.40(2.69,7.21)$ & $2.81(1.49,5.30)$ & 51/370 (13.8\%) & $20.18(10.64,38.29)$ & $8.93(4.07,19.61)$ \\
\hline & & $\mathrm{p}<0.001$ & $p=0.001$ & & $\mathbf{p}<\mathbf{0 . 0 0 1}$ & $\mathrm{p}<0.001$ \\
\hline \multicolumn{7}{|l|}{$\begin{array}{l}\text { Has } \\
\text { comorbidities }\end{array}$} \\
\hline No & 21/552 (3.8\%) & 1.00 [Ref] & 1.00 [Ref] & $4 / 581(0.7 \%)$ & 1.00 [Ref] & 1.00 [Ref] \\
\hline \multirow[t]{2}{*}{ Yes } & $34 / 410(8.3 \%)$ & $3.67(1.62,8.34)$ & $2.02(0.83,4.87)$ & $26 / 428(6.1 \%)$ & $10.01(2.99,33.57)$ & $2.91(0.93,9.05)$ \\
\hline & & $p=0.002$ & $\mathrm{p}=0.12$ & & $p<0.001$ & $\mathrm{p}=0.066$ \\
\hline \multicolumn{7}{|l|}{ BMI } \\
\hline$<30$ & $26 / 624(4.2 \%)$ & 1.00 [Ref] & 1.00 [Ref] & $17 / 656(2.6 \%)$ & 1.00 [Ref] & 1.00 [Ref] \\
\hline$\geq 30$ & 29/338 (8.6\%) & $3.29(1.49,7.26)$ & $4.45(1.90,10.45)$ & 13/353 (3.7\%) & $1.05(0.48,2.28)$ & $1.93(0.83,4.51)$ \\
\hline
\end{tabular}




\begin{tabular}{|c|c|c|c|c|c|c|}
\hline & & $p=0.003$ & $p=0.001$ & & $p=0.90$ & $\mathrm{p}=0.13$ \\
\hline \multicolumn{7}{|l|}{$\begin{array}{l}\text { Current } \\
\text { smoker }\end{array}$} \\
\hline No & 49/861 (5.7\%) & 1.00 [Ref] & 1.00 [Ref] & $28 / 900(3.1 \%)$ & 1.00 [Ref] & 1.00 [Ref] \\
\hline \multirow[t]{2}{*}{ Yes } & 6/101 (5.9\%) & $1.05(0.31,3.54)$ & $1.28(0.35,4.69)$ & 2/109 (1.8\%) & $0.78(0.18,3.39)$ & $1.14(0.23,5.75)$ \\
\hline & & $\mathrm{p}=0.94$ & $\mathrm{p}=0.71$ & & $\mathrm{p}=0.74$ & $\mathrm{p}=0.87$ \\
\hline
\end{tabular}

Analysis by multilevel mixed-effects logistic regression, estimating OR (95\% CI). ${ }^{\mathrm{a}}$ Multivariable models adjusted for age, sex, MS phenotype, and EDSS. Abbreviations: EDSS = Expanded Disability Status Scale; MS = multiple sclerosis; OR = odds ratio; RRMS = relapsing-remitting multiple sclerosis. Results in boldface denote statistical significance $(\mathrm{p}<0.05)$. 
Table 4. Characteristics of COVID-19 severity outcomes, DMTs vs dimethyl fumarate, anti-CD20 DMTs vs all other DMTs, and anti-CD20 DMTs vs natalizumab, suspected+confirmed COVID-19.

\begin{tabular}{|c|c|c|c|c|c|c|}
\hline & Hospitalisation & & & ICU admission & & \\
\hline & $\mathrm{n}(\%)$ & OR (95\% CI) & $\mathrm{aOR}(95 \% \mathrm{CI})^{\mathrm{a}}$ & $\mathrm{n}(\%)$ & OR (95\% CI) & $\mathrm{aOR}(95 \% \mathrm{CI})^{\mathrm{a}}$ \\
\hline \multicolumn{7}{|l|}{ DMT } \\
\hline Untreated & 97/266 (36.5\%) & $3.34(2.17,5.16)$ & $1.79(1.12,2.87)$ & 17/261 (6.5\%) & $2.62(1.06,6.48)$ & $1.36(0.52,3.55)$ \\
\hline Alemtuzumab & $3 / 30(10.0 \%)$ & $0.70(0.20,2.47)$ & $0.86(0.24,3.07)$ & 1/30 (3.3\%) & $1.41(0.16,12.09)$ & $1.93(0.22,16.77)$ \\
\hline Cladribine & 2/27 (7.4\%) & $0.60(0.13,2.72)$ & $0.67(0.14,3.16)$ & $0 / 27(0.0 \%)$ & & \\
\hline Dimethyl fumarate & 38/268 (14.2\%) & 1.00 [Ref] & 1.00 [Ref] & $7 / 259(2.7 \%)$ & 1.00 [Ref] & 1.00 [Ref] \\
\hline Fingolimod & $16 / 195(8.2 \%)$ & $0.60(0.32,1.11)$ & $0.64(0.34,1.21)$ & $4 / 193(2.1 \%)$ & $0.80(0.23,2.79)$ & $0.90(0.25,3.19)$ \\
\hline Glatiramer acetate & 16/86 (18.6\%) & $1.36(0.71,2.61)$ & $1.06(0.53,2.10)$ & $0 / 86(0.0 \%)$ & & \\
\hline Interferon & 17/119 (14.3\%) & $1.11(0.59,2.11)$ & $0.89(0.46,1.70)$ & $2 / 118(1.7 \%)$ & $0.62(0.13,3.10)$ & $0.54(0.11,2.73)$ \\
\hline Natalizumab & $24 / 212(11.3 \%)$ & $0.84(0.48,1.46)$ & $0.82(0.47,1.45)$ & $6 / 209(2.9 \%)$ & $1.07(0.35,3.25)$ & $1.11(0.36,3.43)$ \\
\hline Ocrelizumab & $116 / 463(25.1 \%)$ & $2.14(1.41,3.24)$ & $1.56(1.01,2.41)$ & $37 / 463$ (8.0\%) & $3.00(1.30,6.89)$ & $2.30(0.98,5.39)$ \\
\hline Rituximab & $70 / 252(27.8 \%)$ & $3.12(1.92,5.07)$ & $2.43(1.48,4.02)$ & $24 / 251(9.6 \%)$ & $4.63(1.86,11.49)$ & $3.93(1.56,9.89)$ \\
\hline Teriflunomide & 14/93 (15.1\%) & $1.21(0.61,2.38)$ & $0.85(0.42,1.72)$ & $4 / 93(4.3 \%)$ & $1.59(0.45,5.59)$ & $1.15(0.32,4.14)$ \\
\hline Other DMT & 16/68 (23.5\%) & $2.09(1.07,4.09)$ & $1.10(0.54,2.24)$ & $4 / 67(6.0 \%)$ & $2.34(0.66,8.33)$ & $1.27(0.34,4.72)$ \\
\hline $\begin{array}{l}\text { Pooled Other } \\
\text { DMT }\end{array}$ & $\begin{array}{c}144 / 1082 \\
(13.3 \%)\end{array}$ & 1.00 [Ref] & 1.00 [Ref] & 28/1082 (2.6\%) & 1.00 [Ref] & 1.00 [Ref] \\
\hline Ocrelizumab & $116 / 463(25.1 \%)$ & $2.15(1.62,2.87)$ & $1.75(1.29,2.38)$ & $37 / 463(8.0 \%)$ & $3.08(1.83,5.17)$ & $2.55(1.49,4.36)$ \\
\hline Rituximab & 70/251 (27.9\%) & $3.16(2.17,4.61)$ & $2.76(1.87,4.07)$ & $24 / 251(9.6 \%)$ & $4.69(2.49,8.83)$ & $4.32(2.27,8.23)$ \\
\hline No DMT & 97/261 (37.2\%) & $3.49(2.54,4.80)$ & $2.05(1.43,2.94)$ & 17/261 (6.5\%) & $2.69(1.43,5.04)$ & $1.52(0.77,3.02)$ \\
\hline Natalizumab & 24/209 (11.5\%) & 1.00 [Ref] & 1.00 [Ref] & $6 / 209(2.9 \%)$ & 1.00 [Ref] & 1.00 [Ref] \\
\hline Ocrelizumab & $116 / 463(25.1 \%)$ & $2.64(1.64,4.25)$ & $1.86(1.13,3.07)$ & $37 / 463(8.0 \%)$ & $2.89(1.18,7.05)$ & $2.13(0.85,5.35)$ \\
\hline Rituximab & 70/251 (27.9\%) & $3.16(1.89,5.26)$ & $2.88(1.68,4.92)$ & 24/251 (9.6\%) & $4.17(1.55,11.18)$ & $3.23(1.17,8.91)$ \\
\hline
\end{tabular}




\begin{tabular}{|c|c|c|c|c|c|c|}
\hline & Ventilation & & & Death & & \\
\hline & $\mathrm{n}(\%)$ & OR $(95 \% \mathrm{CI})$ & $\mathrm{aOR}(95 \% \mathrm{CI})^{\mathrm{a}}$ & $\mathrm{n}(\%)$ & OR (95\% CI) & $\mathrm{aOR}(95 \% \mathrm{CI})^{\mathrm{a}}$ \\
\hline \multicolumn{7}{|l|}{ DMT } \\
\hline Untreated & $18 / 261(6.9 \%)$ & $2.51(1.00,6.26)$ & $1.31(0.49,3.49)$ & $27 / 261(10.3 \%)$ & $5.69(2.13,15.19)$ & $1.64(0.56,4.80)$ \\
\hline Alemtuzumab & $1 / 30(3.3 \%)$ & $0.98(0.11,8.63)$ & $1.27(0.14,11.34)$ & $1 / 30$ (3.3\%) & $2.10(0.23,19.15)$ & $2.11(0.19,23.29)$ \\
\hline Cladribine & $0 / 27(0.0 \%)$ & & & $0 / 27(0.0 \%)$ & & \\
\hline Dimethyl fumarate & $7 / 259(2.7 \%)$ & 1.00 [Ref] & 1.00 [Ref] & $5 / 259(1.9 \%)$ & 1.00 [Ref] & 1.00 [Ref] \\
\hline Fingolimod & $5 / 193(2.6 \%)$ & $0.76(0.23,2.50)$ & $0.79(0.24,2.67)$ & $0 / 193(0.0 \%)$ & & \\
\hline Glatiramer acetate & $0 / 86(0.0 \%)$ & & & $2 / 86(2.3 \%)$ & $1.05(0.20,5.57)$ & $0.56(0.10,3.25)$ \\
\hline Interferon & $1 / 118(0.8 \%)$ & $0.21(0.02,1.75)$ & $0.18(0.02,1.52)$ & $1 / 118(0.8 \%)$ & $0.58(0.07,5.20)$ & $0.31(0.03,2.82)$ \\
\hline Natalizumab & $4 / 209$ (1.9\%) & $0.74(0.21,2.59)$ & $0.72(0.20,2.55)$ & $3 / 209$ (1.4\%) & $0.78(0.18,3.33)$ & $0.72(0.16,3.30)$ \\
\hline Ocrelizumab & $18 / 463(3.9 \%)$ & $1.48(0.60,3.66)$ & $1.04(0.41,2.64)$ & $12 / 463(2.6 \%)$ & $1.22(0.42,3.56)$ & $0.49(0.16,1.52)$ \\
\hline Rituximab & $24 / 251(9.6 \%)$ & $5.11(2.01,12.99)$ & $4.00(1.54,10.39)$ & $7 / 251(2.8 \%)$ & $2.61(0.76,8.96)$ & $1.22(0.35,4.18)$ \\
\hline Teriflunomide & 4/93 (4.3\%) & $1.33(0.37,4.79)$ & $0.83(0.22,3.10)$ & 1/93 (1.1\%) & $0.59(0.07,5.21)$ & $0.27(0.03,2.53)$ \\
\hline Other DMT & $2 / 67(3.0 \%)$ & $1.12(0.22,5.71)$ & $0.61(0.12,3.21)$ & $4 / 67(6.0 \%)$ & $3.82(0.97,15.00)$ & $1.05(0.25,4.45)$ \\
\hline $\begin{array}{l}\text { Pooled Other } \\
\text { DMT }\end{array}$ & $24 / 1082(2.2 \%)$ & 1.00 [Ref] & 1.00 [Ref] & 17/1082 (1.6\%) & 1.00 [Ref] & 1.00 [Ref] \\
\hline Ocrelizumab & $18 / 463(3.9 \%)$ & $1.99(1.04,3.80)$ & $1.60(0.82,3.14)$ & $12 / 463(2.6 \%)$ & $1.38(0.65,2.96)$ & $0.76(0.34,1.69)$ \\
\hline Rituximab & $24 / 251(9.6 \%)$ & $6.95(3.54,13.64)$ & $6.15(3.09,12.27)$ & $7 / 251(2.8 \%)$ & $2.94(1.12,7.72)$ & $1.90(0.73,4.93)$ \\
\hline No DMT & $18 / 261(6.9 \%)$ & $3.42(1.78,6.57)$ & $2.07(1.01,4.22)$ & $27 / 261(10.3 \%)$ & $6.47(3.40,12.33)$ & $2.53(1.24,5.15)$ \\
\hline Natalizumab & $4 / 209(1.9 \%)$ & 1.00 [Ref] & 1.00 [Ref] & $3 / 209$ (1.4\%) & 1.00 [Ref] & 1.00 [Ref] \\
\hline Ocrelizumab & $18 / 463(3.9 \%)$ & $2.11(0.69,6.39)$ & $1.34(0.42,4.24)$ & $12 / 463(2.6 \%)$ & $1.64(0.45,5.96)$ & $0.53(0.13,2.24)$ \\
\hline Rituximab & $24 / 251(9.6 \%)$ & $7.52(2.37,23.81)$ & $5.52(1.71,17.84)$ & $7 / 251(2.8 \%)$ & $2.96(0.66,13.29)$ & $1.70(0.38,7.62)$ \\
\hline
\end{tabular}

Analysis by multilevel mixed-effects logistic regression, estimating OR (95\% CI). ${ }^{a}$ Multivariable models adjusted for age, sex, MS phenotype, and EDSS. Abbreviations: DMT = disease-modifying therapy; EDSS = Expanded Disability Status Scale; ICU = Intensive Care Unit; MS = multiple sclerosis; OR = odds ratio. Results in boldface denote statistical significance $(\mathrm{p}<0.05)$. 
medRxiv preprint doi: https://doi.org/10.1101/2021.02.08.21251316; this version posted February 10, 2021. The copyright holder for this preprint (which was not certified by peer review) is the author/funder, who has granted medRxiv a license to display the preprint in perpetuity.

All rights reserved. No reuse allowed without permission. 